\title{
Depression and Coping Among COVID-19-Infected Individuals After 10 Days of Mandatory in-Hospital Quarantine, Irbid, Jordan
}

This article was published in the following Dove Press journal: Psychology Research and Behavior Management

\author{
Shaher M Samrah (iD) \\ Abdel-Hameed Al- \\ Mistarehi $\mathbb{D}^{2}$ \\ Abdelwahab J Aleshawi ${ }^{3}$ \\ Aws G Khasawneh ${ }^{4}$ \\ Suleiman M Momany (D) \\ Baker S Momany (D) ${ }^{3}$ \\ Faris J Abu Za'nouneh $\mathbb{D}^{3}$ \\ Thekra Keelani $\mathbb{D}^{3}$ \\ Abrar Alshorman (iD ${ }^{3}$ \\ Basheer Y Khassawneh (1D) \\ 'Department of Internal Medicine, \\ Faculty of Medicine, Jordan University of \\ Science and Technology (JUST), Irbid, \\ Jordan; ${ }^{2}$ Department of Public Health and \\ Family Medicine, Faculty of Medicine, \\ Jordan University of Science and \\ Technology (JUST), Irbid, Jordan; ${ }^{3}$ Faculty \\ of Medicine, Jordan University of Science \\ and Technology (JUST), Irbid, Jordan; \\ ${ }^{4}$ Department of Neurosciences, Faculty \\ of Medicine, Jordan University of Science \\ and Technology (JUST), Irbid, Jordan
}

Background: In-hospital mandatory quarantine of asymptomatic and symptomatic COVID19-infected individuals was part of the national control strategy used to prevent the spread of the COVID-19 outbreak in Jordan. This study aims to evaluate depression, associated stressors, and various coping methods used among adult quarantined COVID-19-infected individuals.

Methods: This cross-sectional study included all COVID-19-infected individuals who were obligatorily quarantined at King Abdullah University Hospital, Irbid, Jordan from March 15 to April 20, 2020. Symptoms of depression were assessed using the 9-item Patient Health Questionnaire after 10 days of quarantine. In addition, several questions regarding the patients' sights with the health-care system, and coping methods were added. Demographic characteristics, clinical presentation, and comorbidities were collected from the medical records.

Results: Out of 91 quarantined COVID-19 patients, a total of 66 completed the survey, with a participation rate of $72.5 \%$. The majority were relatively young; the mean $\pm \mathrm{SD}$ age was $35.8 \pm$ 16.2 years (range $18-79$ ), 59.1\% were females and $47 \%$ were asymptomatic. A considerable proportion of patients $(44 \%)$ reported symptoms of depression, with $21 \%$ were at high risk of major depressive disorder. Depression symptoms were significantly more common among females than males [PHQ-9 score $\geq 10$ : $13(92.9 \%)$ vs 1 (7.1\%), respectively; $p=0.004]$. The majority of patients $(71.2 \%)$ reported having problems with health-care services. Insufficient involvement in making treatment decisions was the most commonly reported concern $(59.1 \%)$. Patients who reported problems in maintaining privacy, reaching out to their physicians, or receiving conflicting information from the medical staff, had more symptoms of depression compared with the satisfied ones $(p<0.05)$. On the other hand, those who were receiving sufficient support from the family, friends, or medical staff during quarantine, were less likely to have depression symptoms $(p<0.05)$. Furthermore, symptoms of depression were less in patients who stayed in touch with others using phone calls, texting, or social media $(p=0.024)$. Conclusion: Symptoms of depression were common among both symptomatic and asymptomatic quarantined COVID-19 patients. The support of family, friends, and medical staff was an essential alleviating factor. Facilitating adequate communication may promote the mental well-being of COVID-19-infected patients and help in reducing the risk of depression during the in-hospital quarantine.

Keywords: COVID-19, coronavirus, SARS-CoV-2, quarantine, depression, psychological disorder

\section{Introduction}

Coronavirus is one of the major pathogens that primarily target the human respiratory system. In December 2019, China reported to the World Health Organization
Correspondence: Shaher M Samrah

Department of Internal Medicine, Faculty of Medicine, Jordan University of Science and Technology (JUST), P.O. Box: 63000I Irbid 22I I0, Jordan

Tel +96227201000

Fax +962 27201064

Email samrah@just.edu.jo

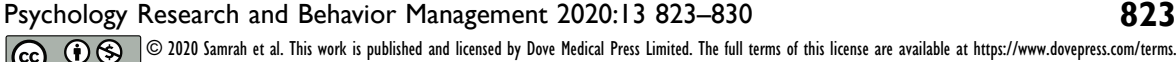

823

DovePress $\mathbf{f}$ in $\boldsymbol{\nabla}$ cc) work you hereby accept the Terms. Non-commercial uses of the work are permitted without any further permission from Dove Medical Press Limited, provided the work is properly attributed. For permission for commercial use of this work, please see paragraphs 4.2 and 5 of our Terms (https://www.dovepress.com/terms.php). 
(WHO) multiple cases of unexplained lower respiratory tract infections. A coronavirus that is genetically related to the SARS virus was identified (SARS-CoV-2). This new viral syndrome named by the WHO as coronavirus disease 2019 (COVID-19). The epidemic spread within mainland China with a basic reproduction number $\left(\mathrm{R}_{0}\right)$ estimated to be from 2.2 to 3.3 and a mortality rate of around $2.3 \%{ }^{1-3}$ In an effort to contain the spread of the COVID-19 infection and reduce its impact on the health-care system, the Jordanian ministry of health has adopted a quarantine system that mandated hospital admission of all laboratoryconfirmed COVID-19 patients, including asymptomatic cases, and regardless of the severity of their illness.

Quarantine is a very old and effective containment tool, previously used to contain the spread of contagious diseases like the plague and influenzas. It is derived from the word "Quarantenaria" which means forty days. ${ }^{4}$ As the COVID-19 pandemic rapidly sweeps across the world, it is inducing considerable psychological effects in the population. Although variable degrees of fear, anxiety, anger, and depression are suspected to be observed in COVID19-infected population during their quarantine, most studies in the literature focused on the psychosocial disturbances among health-care providers and potential contacts of COVID-19 patients. Data indicated high rates of depression, anxiety, and insomnia, posttraumatic stress symptoms (PTSD), and substance use disorders among health-care workers dealing with COVID-19 patients. ${ }^{5-8}$ Studies of individuals who had been quarantined for different contagious diseases showed an increased prevalence of depression, emotional disturbances, stress, insomnia, and irritability. ${ }^{9-11}$ There are scarce data to describe such an impact on the quarantined COVID-19infected population.

To date, this is the first study that aims to evaluate depression, various stressors, and associated factors and coping mechanisms among individuals with confirmed COVID-19 infection during their obligatory and prolonged in-hospital quarantine.

\section{Methods}

\section{Outbreak Response}

Jordan is a Middle Eastern country with a population of 11 million. After the WHO declared COVID-19 as pandemic disease, the Jordanian Ministry of Health issued a health-alert that patients with flu-like symptoms and recent travel to endemic countries should be screened for
SARS-CoV-2 infection. After the first case of COVID-19 infection was reported in Jordan on March 2, 2020, a policy of extensive contact tracing followed by a screening of suspicious contacts, and mandatory hospital admission of all laboratory-confirmed COVID-19 patients was placed. This was supported by a countrywide strict lockdown and a nightly curfew. The borders were sealed off and all traveling to and from Jordan was stopped on March 15, 2020. A Royal Decree has been issued approving the implementation of the National Defense Law on March 17. These strict outbreak response measures applied at early stages probably contributed to the lenient nature of this outbreak and reducing its impact on public health. ${ }^{12}$

\section{Participants and Study Design}

This cross-sectional, survey-based, single-center study included all adults with laboratory-confirmed COVID-19 infection that were obligatorily quarantined at King Abdullah University Hospital (KAUH), Irbid, Jordan from March 15 to April 20, 2020. Patients younger than 18 years were excluded. COVID-19 cases were confirmed by a positive SARS-CoV-2 real-time reverse transcriptasepolymerase chain reaction assay (RT-PCR), from a nasopharyngeal swab specimen. Specimens were collected and analyzed according to the Centers for Disease Control and Prevention (CDC) guidelines. All clinical specimens were tested with the assay developed by the CDC, targeting the N1 and N2 genes. ${ }^{13}$

Clinical charts and nursing records of all included patients were reviewed, and demographic characteristics, clinical presentation, and comorbidities were recorded. The degree of symptoms of depression experienced by participants was assessed using the 9-item Patient Health Questionnaire (PHQ-9) after 10 days of quarantine, and answers were documented by two interviewers. PHQ-9 consists of nine items based directly on the diagnostic criteria for major depressive disorder in the DSM-IV. Based on participant response to the frequency of any particular symptom $(0=$ not at all, $1=$ several days, $2=$ more than half of the days, 3 = nearly every day), a total score ranging from 0 to 27 was obtained, with higher scores indicating patients' increased depression severity. PHQ-9 is a dual-purpose instrument that can establish major depressive disease diagnosis as well as grade the severity of depression. PHQ- 9 score $\geq 10$ had a sensitivity of $88 \%$ and a specificity of $85-88 \%$ for major depressive disorder. ${ }^{14,15}$ Also, PHQ-9 has excellent internal reliability and test-retest reliability. ${ }^{14}$ The total score of the PHQ-9 
questionnaire was interpreted as follows: normal (0-4), mild (5-9), moderate (10-14), and severe (15-21) depression. ${ }^{14,15}$ Also, five questions were obtained from the 15-item Picker Patient Experience Questionnaire (PPE15) to evaluate patients' experiences with specific dimensions of in-patient care during their quarantine in the hospital. ${ }^{16,17}$ The patients' answers for these questions were coded as a dichotomous "problem score", indicating the presence or absence of a problem. A problem is defined as a piece of health care that could, in the eyes of the patient, be improved upon (Appendix 1)..$^{16,17}$ Furthermore, various coping interventions adopted by the patients during their quarantine were addressed and analyzed in relation to the degree of depression.

Quarantine was ended and patients were discharged home when they met all clinical and virologic cure criteria of the CDC which includes; resolution of fever without the use of fever-reducing medication, improvement in respiratory symptoms, and negative results of at least two consecutive nasopharyngeal swab specimens collected $\geq 24$ hours apart. ${ }^{18}$

Approval from the Institutional Review Board (IRB), and the clinical research ethics committee of King Abdullah University Hospital and Jordan University of Science and Technology was received before the initiation of this study. Written informed consent for participation in this study was obtained from all recruited patients. Participants could terminate the survey at any time they desired. The survey was anonymous, and confidentiality of information was assured.

\section{Statistical Analysis}

The data were described using frequency and percentage for categorical variables and mean \pm standard deviation for continuous variables. A chi-square test or Fisher's exact test was used to assess the association between categorical variables, whereas continuous variables were analyzed by the Student's $t$-test or ANOVA. The total scores of PHQ-9 were not normally distributed and so are presented as medians with interquartile ranges (IQRs). A $p$-value of less than 0.05 was considered statistically significant. The IBM Statistical Package for Social Sciences Software (SPSS) for Windows, version 25.0 was used for data processing and analysis.

\section{Results}

After an outbreak was recognized on March 17th, 2020, a total of 91 laboratory-confirmed COVID-19 patients were admitted to KAUH by April 2, 2020. Ten patients were excluded from the study as they were younger than 18 years and two patients were unable to participate because of their critical medical illnesses. Eleven patients declined the survey for privacy concerns, while two refused to give reasons for declining to participate in the study. A total of 66 patients were included in the study, with a participation rate of $72.5 \%$. The majority of patients were relatively young; the mean \pm SD age was $35.8 \pm 16.2$ years (range 18-79) and 59.1\% were females. About half of the patients $(48.5 \%)$ were cigarette or waterpipe smokers, and $20(30.3 \%)$ were obese (BMI $\geq 30 \mathrm{~kg} / \mathrm{m} 2)$. Sixteen $(24.2 \%)$ had chronic illnesses; ischemic heart disease $(6.1 \%)$, hypertension $(15.2 \%)$, dyslipidemia (7.6\%), and diabetes mellitus (7.6\%). About half of the patients (47\%) were asymptomatic on admission and did not develop any symptoms during quarantine (Table 1).

The feedback from patients regarding their experience with specific dimensions of the health-care system during their quarantine inside the hospital is presented in Table 2. Forty-seven patients $(71.2 \%)$ reported having problems with the provided medical care. The largest proportion of problems $(59.1 \%)$ were related to the insufficient involvement of patients in the decisions regarding their medical care and treatment plans. Also, 30.3\% reported problems in reaching out to their physicians, $18.2 \%$ reported receiving conflicting information from doctors and nurses and $10.6 \%$ reported problems related to privacy during the quarantine. The smallest proportion of problems $(7.6 \%)$ were observed for the item asking whether doctors talked in front of them as if they were not there.

When patients were asked about "the most preferred method to cope for feeling isolated during quarantine", $47 \%$ of the patients answered that "staying in touch with their close ones by phone calls and texting helped the most". Using social media, mostly Facebook and YouTube, was the second most commonly used coping method (28.8\%). Moreover, watching television and praying were reported as the preferred coping methods by $10.6 \%$, and $7.6 \%$ of patients, respectively.

Most patients (80.2\%) agreed that receiving emotional support from others was the most important element to help them feel socially connected during their in-hospital quarantine. The largest proportion of patients reported family as the main source of support during quarantine $(65.2 \%)$, followed by friends (50\%), medical staff (39.4\%), and other quarantined COVID-19 patients $(9.1 \%)$. 
Table I Demographic Characteristics, Clinical Features, and Severity Categories of Depression Among Quarantined COVID-19 Patients

\begin{tabular}{|l|l|}
\hline & All Patients, $\mathbf{n}=66$ \\
\hline Age, $\mathrm{m} \pm \mathrm{SD}$ & $35.8 \pm 16.2(\mathrm{I}-79)$ \\
Female gender & $39(59.1 \%)$ \\
Cigarettes or waterpipe smoking & $32(48.5 \%)$ \\
$\quad$ Pack per year, $\mathrm{m} \pm \mathrm{SD}$ & $18.8 \pm 26.8$ \\
Weight $(\mathrm{Kg}), \mathrm{m} \pm \mathrm{SD}$ & $78.1 \pm 17.7$ \\
Height $(\mathrm{cm}), \mathrm{m} \pm \mathrm{SD}$ & $169.1 \pm 8.7$ \\
BMI $\left(\mathrm{Kg} / \mathrm{m}^{2}\right), \mathrm{m} \pm \mathrm{SD}$ & $27.2 \pm 5.3$ \\
Obese $\left(\mathrm{BMI} \geq 30 \mathrm{~kg} / \mathrm{m}^{2}\right)$ & $20(30.3 \%)$ \\
Asymptomatic & $31(47 \%)$ \\
Comorbidities & $16(24.2 \%)$ \\
Diabetes mellitus & $5(7.6 \%)$ \\
Hypertension & $10(15.2 \%)$ \\
Ischemic heart disease & $4(6.1 \%)$ \\
Dyslipidemia & $5(7.6 \%)$ \\
PHQ-9 score, median (IQR) & $3(\mathrm{I}-8)$ \\
\hline PHQ-9, Severity Categories & \\
\hline Normal & $37(56.1 \%)$ \\
Mild & $15(22.7 \%)$ \\
Moderate & $10(15.2 \%)$ \\
Severe & $4(6.1 \%)$ \\
\hline
\end{tabular}

\section{The Severity of Depression and}

\section{Associated Factors}

A considerable proportion of patients (44\%) reported symptoms of depression, with $21 \%$ were at high risk of major depressive disorder as their PHQ-9 score $\geq 10$. Depression symptoms were mainly reported by females [PHQ-9 score $\geq 10$ among women vs men: 13 (92.9\%) vs $1(7.1 \%) ; p=0.004]$. Although variable degrees of depression (mild, moderate, and severe) were observed in 19 patients of the symptomatic group (65.5\%), compared with 10 patients $(34.5 \%)$ who were asymptomatic, there was no significant difference between the two groups ( $p=$ 0.072). Nonetheless, patients who reported problems or concerns regarding maintaining their privacy $(10.6 \%)$, reaching out to their physicians $(30.3 \%)$, or received conflicting or confusing information from the health-care providers $(18.2 \%)$ were found to have more depression symptoms $(p=0.040, \quad p=0.042, \quad p=0.018$; respectively) (Table 3). On the other hand, patients who reported receiving adequate emotional support from their families (65.2\%), friends (50\%), or the medical staff (39.4\%) during quarantine, were less likely to have symptoms of depression in comparison to patients without such support
Table 2 Patients Sights with the Health-Care System During Quarantine Inside the Hospital

\begin{tabular}{|c|c|c|c|c|}
\hline \multirow[t]{2}{*}{ Question } & \multicolumn{4}{|c|}{ All Patients $(n=66)$} \\
\hline & $\begin{array}{l}\text { Yes, } \\
\text { Often }\end{array}$ & $\begin{array}{l}\text { Yes, } \\
\text { Sometimes }\end{array}$ & No & $\begin{array}{l}\text { No } \\
\text { Need to } \\
\text { Talk to } \\
\text { a Doctor }\end{array}$ \\
\hline $\begin{array}{l}\text { Were you given } \\
\text { enough privacy } \\
\text { when discussing } \\
\text { your treatment? }\end{array}$ & \multicolumn{2}{|c|}{59 (89.4\%) } & $\begin{array}{l}7 \\
(10.6 \%)\end{array}$ & - \\
\hline $\begin{array}{l}\text { Did doctors talk } \\
\text { in front of you as } \\
\text { if you were not } \\
\text { there? }\end{array}$ & $\begin{array}{l}\text { I } \\
(1.5 \%)\end{array}$ & $4(6.1 \%)$ & $\begin{array}{l}61 \\
(92.4 \%)\end{array}$ & - \\
\hline $\begin{array}{l}\text { If you needed to } \\
\text { talk to a doctor, } \\
\text { did you get the } \\
\text { opportunity to do } \\
\text { so? }\end{array}$ & $\begin{array}{l}36 \\
(54.5 \%)\end{array}$ & $6(9.1 \%)$ & $\begin{array}{l}14 \\
(21.2 \%)\end{array}$ & $\begin{array}{l}10 \\
(15.2 \%)\end{array}$ \\
\hline $\begin{array}{l}\text { Did you want to } \\
\text { be more involved } \\
\text { in decisions made } \\
\text { about your care? }\end{array}$ & $\begin{array}{l}30 \\
(45.5 \%)\end{array}$ & $9(13.6 \%)$ & $\begin{array}{l}27 \\
(40.9 \%)\end{array}$ & - \\
\hline $\begin{array}{l}\text { Sometimes in the } \\
\text { hospital one } \\
\text { doctor or nurse } \\
\text { will say one thing } \\
\text { and another will } \\
\text { say something } \\
\text { quite different. } \\
\text { Did this happen } \\
\text { to you? }\end{array}$ & $\begin{array}{l}4 \\
(6.1 \%)\end{array}$ & $8(12.1 \%)$ & $\begin{array}{l}54 \\
(81.8 \%)\end{array}$ & - \\
\hline
\end{tabular}

( $p=0.015, p=0.025, p=0.012$; respectively). Patients who chose "staying in touch with others or using social media" as their most preferred ways to cope with quarantine were less likely to have symptoms of depression (Figure 1). Interestingly, among Television (TV) watchers, those who were following COVID-19 related news programs or interviews were more likely to have symptoms of depression, in comparison to those watched random shows or entertainment programs such as movies, TVshows, or series $(p=0.023)$ (Figure 2$)$.

\section{Discussion}

Most studies focused on the clinical presentation and laboratory findings of COVID-19 hospitalized patients 
Table 3 The Factors Associated with a High Risk of Depression During Quarantine Inside the Hospital

\begin{tabular}{|c|c|c|c|c|c|}
\hline & \multicolumn{4}{|c|}{ Severity Categories of Depression, $\mathbf{n}(\%)$} & \multirow[t]{2}{*}{$P$-value } \\
\hline & $\begin{array}{l}\text { Normal } \\
(n=37)\end{array}$ & $\begin{array}{l}\text { Mild } \\
(n=15)\end{array}$ & $\begin{array}{l}\text { Moderate } \\
(n=10)\end{array}$ & $\begin{array}{l}\text { Severe } \\
(n=4)\end{array}$ & \\
\hline Age, $m \pm S D$ & $37.8 \pm 16.3$ & $35.7 \pm 17.3$ & $30.6 \pm 15.1$ & $29.8 \pm 14.0$ & 0.544 \\
\hline Gender (female) & $18(48.6 \%)$ & $8(53.3 \%)$ & $10(100 \%)$ & $3(75 \%)$ & 0.027 \\
\hline Cigarettes smoking & $19(51.4 \%)$ & $9(60 \%)$ & $2(20 \%)$ & $2(50 \%)$ & 0.453 \\
\hline Obese $\left(\mathrm{BMI} \geq 30 \mathrm{~kg} / \mathrm{m}^{2}\right)$ & $14(37.8 \%)$ & $4(26.7 \%)$ & $2(20 \%)$ & 0 & 0.343 \\
\hline Symptomatic & $16(43.2 \%)$ & $9(60 \%)$ & $6(60 \%)$ & $4(100 \%)$ & 0.141 \\
\hline Comorbidities & $10(27 \%)$ & $2(13.3 \%)$ & $3(30 \%)$ & I (25\%) & 0.727 \\
\hline \multicolumn{6}{|c|}{ Patients sights with the health-care system during quarantine } \\
\hline Not given enough privacy when discussing treatment. & $4(10.8 \%)$ & 0 & $\mathrm{I}(10 \%)$ & $2(50 \%)$ & 0.040 \\
\hline Doctors talk in front of the patient as if they were not there. & $3(8.1)$ & I (6.7\%) & $\mathrm{I}(10 \%)$ & 0 & 0.931 \\
\hline Less opportunity to talk to the physician & $8(21.6 \%)$ & $3(20 \%)$ & $6(60 \%)$ & $3(75 \%)$ & 0.042 \\
\hline $\begin{array}{l}\text { Not sufficiently involved in decisions about treatment and } \\
\text { care }\end{array}$ & $20(54.1 \%)$ & $8(53.3 \%)$ & $8(80 \%)$ & $3(75 \%)$ & 0.420 \\
\hline Medical staff gave conflicting information & $2(5.4 \%)$ & $5(33.3 \%)$ & $3(30 \%)$ & $2(50 \%)$ & 0.018 \\
\hline \multicolumn{6}{|l|}{ Most needed source of support during quarantine } \\
\hline Family support & $9(24.3 \%)$ & $4(26.7 \%)$ & $7(70 \%)$ & $3(75 \%)$ & 0.015 \\
\hline Friends support & $13(35.1 \%)$ & $10(66.7 \%)$ & $6(60 \%)$ & $4(100 \%)$ & 0.025 \\
\hline Medical stuff support & $16(43.2 \%)$ & $12(80 \%)$ & $9(90 \%)$ & $3(75 \%)$ & 0.012 \\
\hline Other patients support & 34 (91.9\%) & 14 (93.3\%) & $8(80 \%)$ & $4(100 \%)$ & 0.575 \\
\hline
\end{tabular}

with less attention to the mental health effects of inhospital quarantine. ${ }^{12,19,20}$ This study demonstrates that symptoms of depression were commonly reported among hospitalized COVID-19 patients during their mandatory quarantine, regardless of the severity of their illness. The support and social interaction provided by family, friends, and medical staff were an important alleviating factor during the quarantine of this study population as higher levels of depression were observed among those without such support. Although social media mitigated the effects of quarantine for many patients, most patients compensated for their feeling of isolation by staying-in-touch with family and friends using phone-calls and texting. On the other hand, watching or reading news about COVID-19 during quarantine was associated with higher levels of depression.

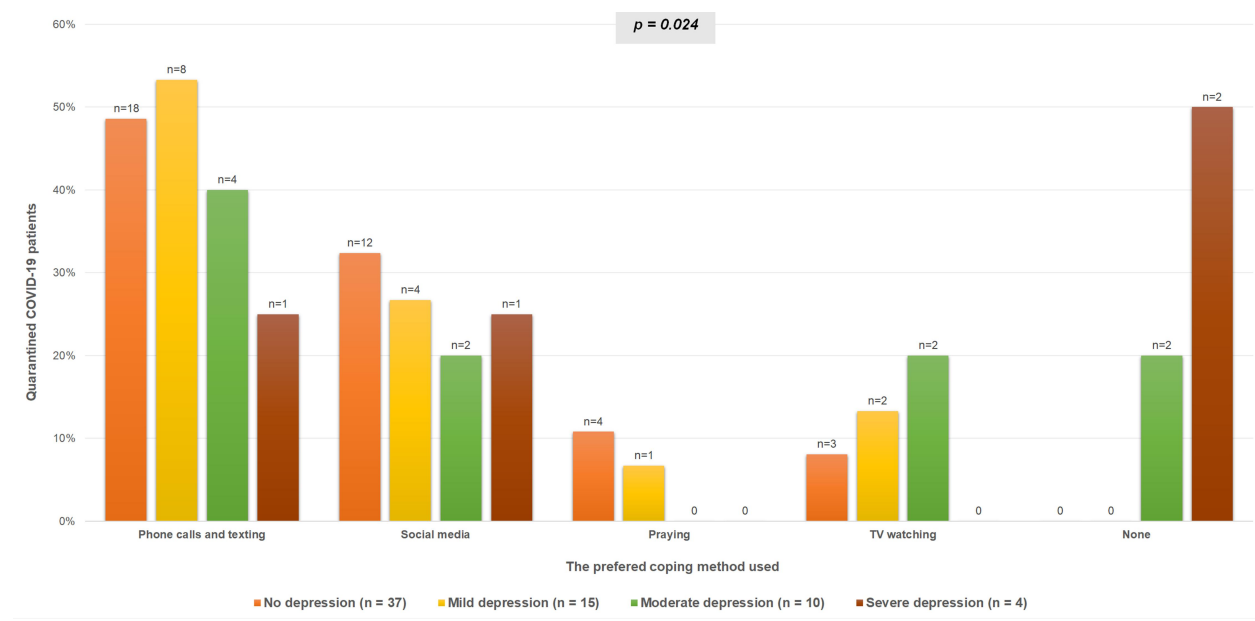

Figure I The association between the preferred coping methods used during quarantine and depression. 


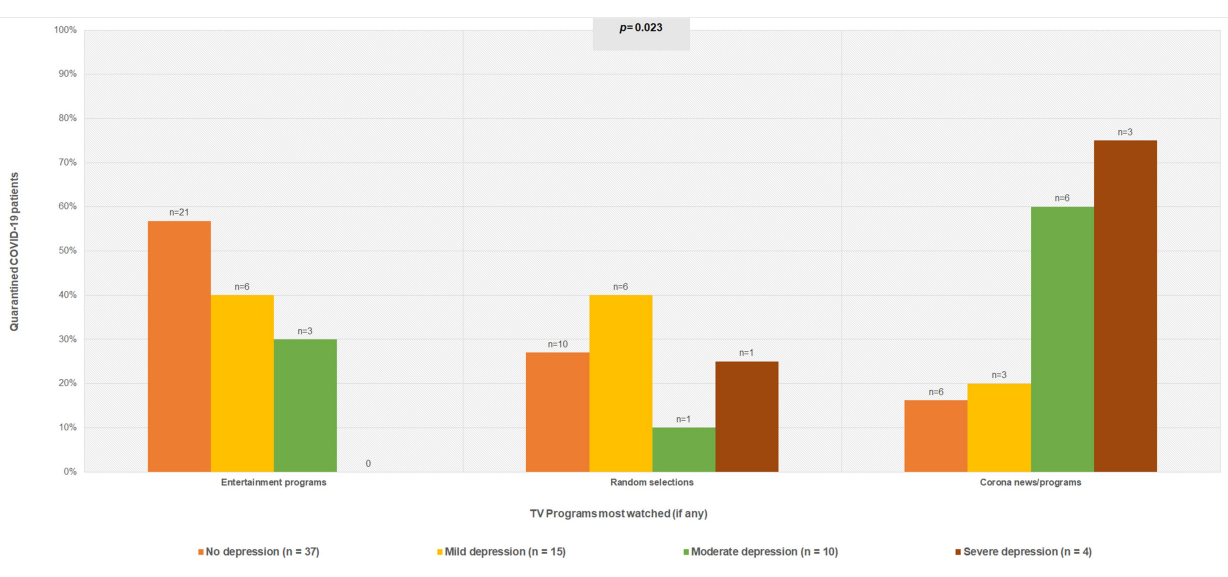

Figure 2 The association between the most watched Television (TV) programs and depression.

The Centers for Disease Control and Prevention (CDC) had warned that COVID-19 outbreaks can be stressful; and patients' fear and anxiety about their health can be overwhelming. ${ }^{21}$ Fear and anxiety of the health-care providers from having close encounters with COVID-19 cases resulted in limited close comprehensive face-to-face encounters. Unfortunately, this unintended behavior has generated a feeling of despair among COVID-19 patients who implied multiple drawbacks including insufficient time spent by the health-care providers with less opportunity to talk to the caring medical teams and disconnected communication between the members of the caring medical team and the patients. Lack of clarity about different risk levels and poor communication were cited as a stressor in developing the psychological disorder in quarantined patients. ${ }^{22-24}$ Privacy concerns while discussing treatment plans, receiving conflicting reports from the caring medical team, and difficulty in reaching out to physicians were among the most reported health-care problems. Patients who reported these problems were more likely to have symptoms of depression.

Quarantine is one of several public health measures to prevent the spread of infectious diseases. Quarantine restricted measures were regularly associated with negative psychosocial effects and distress that may include depression, anxiety, anger, stress, social isolation, loneliness, PTSD, and stigmatization. ${ }^{9,25}$ Sense of uncertainty due to fear for one's health or the health of loved ones, disruption to daily life, and isolation as a result of separation from others, were all experienced. ${ }^{26}$ The high transmission rate of COVID-19 and its high morbidity and mortality may have intensified the perception of personal danger and escalated the risk of developing the psychological disorder than caused by quarantine alone. Those quarantined for longer than 10 days showed significantly higher posttraumatic stress symptoms than those quarantined for less than 10 days. ${ }^{27} \mathrm{~A}$ study examined symptoms of depression 3 years after quarantine and found that $9 \%$ of the whole sample reported high depressive symptoms. ${ }^{28}$ Negative psychosocial outcomes were also reported among health-care workers who are treating patients with coronavirus disease. ${ }^{5,22}$ Addressing the possible negative impact of quarantine is an important aspect of maintaining the overall health well-being and should be part of the overall assessment and medical care plan provided to patients requiring quarantine.

This study has several limitations. First, the sample size is small which limits the generalization of our findings and increases the risk of selection bias. Second, the study was carried out after 10 days of quarantine and lacks longitudinal follow-up. Some patients remained in quarantine for longer periods with a progressively stressful situation which might have led to a higher risk of depression and stress. Third, although the response rate of this study was $72.5 \%$, response-bias may have occurred if the non-responders refused the survey as they were feeling uninterested or depressed to participate. Fourth, potential differences need to be considered as this study did not have a control inpatient group to compare the prevalence and severity of depression.

\section{Conclusion}

Symptoms of depression were commonly reported among COVID-19 patients during their in-hospital obligatory 
quarantine regardless of the severity of their disease. Receiving the support of family, friends, and medical staff was an essential alleviating factor, and connecting with them was the most preferred coping method. On the other hand, following the media for news about the coronavirus correlated with higher levels of depression symptoms. These findings suggest that administrative measures to facilitate adequate communication between these patients and their families, friends, and medical staff and limiting coronavirus news exposure during in-hospital quarantine may lower the risk of depression. Further large epidemiological studies and clinical trials are needed to investigate the mental health effect of the quarantine and how to reduce it.

\section{Data Sharing Statement}

The datasets generated and analyzed during the current study are available with the corresponding author.

\section{Compliance with Ethical Standards}

All procedures performed in this study involving human participants were reviewed and ethically approved by the Institutional Review Board (IRB) of Jordan University of Science and Technology and King Abdullah University Hospital. This study was conducted following the 1964 Helsinki declaration and its later amendments or comparable ethical standards.

\section{Informed Consent}

Written informed consent was obtained from all individual participants included in the study.

\section{Acknowledgments}

We acknowledge all health-care workers involved in the diagnosis and treatment of patients in KAUH. We thank Ali Banni Issa, Enas Bataienh, Heba Al Zamel, and Reem Qudisat for their assistance. We also extend our sincere thanks to Randa S. Samrah for her contributions to manuscript language revision.

\section{Funding}

No funding was received for this study.

\section{Disclosure}

The authors declare that they have no competing interests in this work.

\section{References}

1. Li Q, Guan X, Wu P, et al. Early transmission dynamics in Wuhan, China, of novel coronavirus-infected pneumonia. $N$ Engl J Med. 2020;382(13):1199-1207. doi:10.1056/NEJMoa2001316

2. Liu Y, Gayle AA, Wilder-Smith A, Rocklöv J. The reproductive number of COVID-19 is higher compared to SARS coronavirus. J Travel Med. 2020.

3. The Novel Coronavirus Pneumonia Emergency Response Epidemiology Team. The epidemiological characteristics of an outbreak of 2019 novel Coronavirus Diseases (COVID-19) - china, 2020. China CDC Wkly. 2020;2(8):113-122. doi:10.46234/ ccdcw2020.032

4. Newman KL. Shutt up: bubonic plague and quarantine in early modern England. J Soc Hist. 2012;45(3):809-834. doi:10.1093/jsh/ shr114

5. Lai J, Ma S, Wang Y, et al. Factors associated with mental health outcomes among health care workers exposed to coronavirus disease 2019. JAMA Netw Open. 2020;3(3):e203976. doi:10.1001/ jamanetworkopen.2020.3976

6. Gold JA. Covid-19: adverse mental health outcomes for healthcare workers. BMJ. 2020;369:m1815. doi:10.1136/bmj.m1815

7. Adams JG, Walls RM. Supporting the health care workforce during the COVID-19 global epidemic. JAMA. 2020;323(15):1439. doi:10.1001/jama.2020.3972

8. Rossi R, Socci V, Pacitti F, et al. Mental health outcomes among front and second line health workers associated with the COVID-19 pandemic in Italy. medRxiv. 2020.

9. Brooks S, Webster R, Smith L, et al. The psychological impact of quarantine and how to reduce it: rapid review of the evidence. Lancet. 2020;395(10227):912-920. doi:10.1016/S0140-6736(20) 30460-8

10. DiGiovanni C, Conley J, Chiu D, Zaborski J. Factors influencing compliance with quarantine in Toronto during the 2003 SARS outbreak. Biosecur Bioterror. 2004;2(4):265-272. doi:10.1089/ bsp.2004.2.265

11. Lee S, Chan LYY, Chau AMY, Kwok KPS, Kleinman A. The experience of SARS-related stigma at amoy gardens. Soc Sci Med. 2005;61 (9):2038-2046. doi:10.1016/j.socscimed.2005.04.010

12. Samrah SM, Al-Mistarehi A-HW, Ibnian AM, et al. Covid-19 outbreak in Jordan: epidemiological features, clinical characteristics, and laboratory findings. Ann Med Surg. 2020;57:103-108. doi:10.1016/j. amsu.2020.07.020.

13. Centers for Disease Control and Prevention. Coronavirus disease 2019 (COVID-19). 2020. Information for Laboratories about Coronavirus (COVID-19) Available from: https://www.cdc.gov/coro navirus/ 2019-ncov/lab/rt-pcr-detection-instructions.html. Accessed August 20, 2020.

14. Kroenke K, Spitzer RL, Williams JB. The PHQ-9: validity of a brief depression severity measure. J Gen Intern Med. 2001;16(9):606-613. doi:10.1046/j.1525-1497.2001.016009606.x

15. Levis B, Benedetti A, Thombs BD. Accuracy of Patient Health Questionnaire-9 (PHQ-9) for screening to detect major depression: individual participant data meta-analysis. BMJ. 2019;365:11476. doi:10.1136/bmj.11476

16. Jenkinson C, Coulter A, Bruster S. The picker patient experience questionnaire: development and validation using data from in-patient surveys in five countries. Int $J$ Qual Health Care. 2002;14 (5):353-358. doi:10.1093/intqhe/14.5.353

17. Jenkinson C, Coulter A, Bruster S, Richards N, Chandola T. Patients' experiences and satisfaction with health care: results of a questionnaire study of specific aspects of care. Qual Saf Health Care. 2002;11:335-339. doi:10.1136/qhc.11.4.335 
18. Centers for Disease Control and Prevention. Coronavirus disease 2019 (COVID-19). Healthcare professionals. Clinical Care. Available from: https://www.cdc.gov/coronavirus/2019-ncov/hcp/dis position-hospitalized-patients.html. Accessed August 20, 2020.

19. Lovato A, de Filippis C. Clinical presentation of COVID-19: a systematic review focusing on upper airway symptoms. Ear Nose Throat J. 2020;014556132092076. doi:10.1177/0145561320920762

20. Guan WJ, Ni ZY, Hu Y, et al. Clinical characteristics of coronavirus disease 2019 in China. N Engl J Med. 2020;382(18):1708-1720. doi:10.1056/NEJMoa2002032

21. Centers for Disease Control and Prevention. Coronavirus disease 2019 (COVID-19). Daily life and coping. Stress and Coping. Available from: https://www.cdc.gov/coronavirus/ 2019-ncov/dailylife-coping/managing-stress-anxiety.html?CDC_AA_refVal $=\mathrm{https} \%$ $3 \mathrm{~A} \% 2 \mathrm{~F} \% 2 \mathrm{Fwww} . \mathrm{cdc}$.gov\%2Fcoronavirus\%2F $2019-\mathrm{ncov} \%$ 2Fprepare\%2Fmanaging-stress-anxiety.html\#stressful. Accessed August 20, 2020.

22. Robertson E, Hershenfield K, Grace SL, Stewart DE. The psychosocial effects of being quarantined following exposure to SARS: a qualitative study of Toronto health care workers. Can J Psychiatry. 2004;49:403-407. doi:10.1177/070674370404900612

23. Desclaux A, Badji D, Ndione AG, Sow K. Accepted monitoring or endured quarantine? Ebola contacts' perceptions in Senegal. Soc Sci Med. 2017;178:38-45. doi:10.1016/j.socscimed.2017.02.009
24. Braunack-Mayer A, Tooher R, Collins JE, Street JM, Marshall H. Understanding the school community's response to school closures during the H1N1 2009 influenza pandemic. BMC Public Health. 2013;13(1):344. doi:10.1186/1471-2458-13-344

25. Röhr S, Müller F, Jung F, et al. Psychosocial impact of quarantine measures during serious coronavirus outbreaks: a rapid review. Psychiatrische Praxis. 2020;47(4):179-189. doi:10.1055/a-11595562

26. Cava MA, Fay KE, Beanlands HJ, et al. The experience of quarantine for individuals affected by SARS in Toronto. Public Health Nurs. 2005;22(5):398-406. doi:10.1111/j.0737-1209.2005.220504.x

27. Hawryluck L, Gold WL, Robinson S, Pogorski S, Galea S, Styra R. SARS control and psychological effects of quarantine, Toronto, Canada. Emerg Infect Dis. 2004;10(7):1206-1212. doi:10.3201/ eid1007.030703

28. Liu X, Kakade M, Fuller CJ, et al. Depression after exposure to stressful events: lessons learned from the severe acute respiratory syndrome epidemic. Compr Psychiatry. 2012;53(1):15-23. doi:10.1016/j.comppsych.2011.02.003
Psychology Research and Behavior Management

\section{Publish your work in this journal}

Psychology Research and Behavior Management is an international, peer-reviewed, open access journal focusing on the science of psychology and its application in behavior management to develop improved outcomes in the clinical, educational, sports and business arenas. Specific topics covered in the journal include: Neuroscience, memory and decision making; Behavior modification and management; Clinical

\section{Dovepress}

applications; Business and sports performance management; Social and developmental studies; Animal studies. The manuscript management system is completely online and includes a very quick and fair peer-review system, which is all easy to use. Visit http://www. dovepress.com/testimonials.php to read real quotes from published authors. 